\title{
Article
}

\section{Study on the Spatial Pattern of Innovation Output and Influencing Factors in Guangdong-Hong Kong-Macao Greater Bay Area}

\author{
Dongliang Yang ${ }^{1,2}$, Chunfeng $\mathrm{Li}^{1}$ \\ 1 Northeast Asian Studies College, Jilin University, Changchun130012, China \\ 2 Northeast Asian Studies College, Jilin University, Changchun130012, China; \\ yangdl@jlu.edu.cn \\ * Correspondence: yangdl@jlu.edu.cn(D.L.) ; Tel.:+86-133-644-760-70
}

\begin{abstract}
The advantageous location, port clusters, strong economic strength, developed financial system, rational and orderly urban division of labor and modern industrial system of Guangdong-Hong Kong-Macao greater bay area provide sustainable driving force for innovation activities in this region. This paper selected the Gini-coefficient, first degree index and concentration index to measure the spatial pattern characteristics of innovation output in Guangdong-Hong Kong-Macao greater bay area. The results show that the innovation output presented a spatial pattern of center-periphery in the study region with Shenzhen and Guangzhou as the dual centers and engines of innovation and Dongguan and Foshan as the main innovative areas. Further empirical analysis of the impact of various factors on innovation output in the study region found that R\&D expenditure, the number of R\&D personnel, the level of economic development and industrial structure all have significant promoting effects on innovation output. Accordingly, this paper put forward countermeasures and suggestions to promote the innovative development of Guangdong-Hong Kong-Macao greater bay area and build a world-class scientific and technological innovation bay area.
\end{abstract}

Keywords: Guangdong-Hong Kong-Macao Greater Bay Area; Innovation sustainable development; Innovation output; Spatial pattern; Empirical study.

\section{Introduction}

Based on the practical experience of bay area development, world-class bay areas often have a strong innovation system, which drives the sustainable development of economy in these areas. In terms of China's regional development strategies, innovative sustainable development is the key to building innovative regions and enhancing regional competitiveness. In July 2017, Chinese President $\mathrm{Xi}$ Jinping proposed the construction of Guangdong-Hong Kong-Macao greater bay area at the conference for celebrating the 20th anniversary of Hong Kong's return to China. The Guangdong-Hong Kong-Macao greater bay area will be an important engine of China's economic growth and is an inevitable choice for building a scientific and innovative bay area in China. The 2018 Global Innovation Index Report (GII), jointly published by the World Intellectual Property Organization (WIPO), Cornell University and the European Business School, shows that China has made remarkable achievements in innovation clusters, among which Shenzhen-Hong Kong ranks second in the world as a regional innovation cluster, and especially Guangdong, Hong Kong and Macau have increasingly become world-class technological innovation centers. ${ }^{1}$

Innovation is the key driving force for the long-term and high-speed sustainable growth of regional economy [1-5]. The new economic growth theory holds that the progress of knowledge and technology has become an important driver for modern economic growth [6]. The role of innovation

${ }^{1}$ Data source: https://www.wipo.int/portal/en/index.html. 
in economic growth was first noted by Joseph Schumpeter, who identified the central role of entrepreneurship and technological innovation as forces of change. He initially remarked on the role of innovative entrepreneurs and the disruptive nature of innovations [7], and later he highlighted the relevance of $R \& D$ activities undertaken within large corporations [8]. In parallel, since the influential papers by Jaffe $(1986,1989)$ [9,10] and Griliches (1990) [11], empirical studies of knowledge production functions, conducted at the national, regional and firm levels, have provided powerful evidence of the key role of knowledge inputs (namely, R\&D expenditures) in generating knowledge outputs (namely, patent intensity) at all levels of analysis [12-14]. Importantly, they have confirmed the unbalanced spatial distribution of knowledge production and have opened the debate on the geographical reach of knowledge flows, as well as on the main mechanisms and channels directing them [15-21].

Current research on innovation mainly focuses on four aspects. One is the scientific nature of the indicators of innovation ability and the study of patents. Pavitt (1982) conducted research on innovation activities in 17 countries, industries and companies in the United States and the European Union, and found that the use of patent statistics and R\&D statistics to measure innovation ability can underestimate a country's and a company's ability to innovate, respectively[22]. Acs et al. (2002) divided innovation measurement into three aspects: using R\&D expenditure as a measure of innovation input, using the number of patent applications as a measure in the innovation process, and using the number of patents granted as a measure of innovation output [23]. It was found that in regional spillover model, the use of patents and innovation as a measure of technological change produce similar results. Jalles (2010) used intellectual property index and the number of patents as alternative variables to measure innovation [24]. An empirical test of panel data from 73 countries between 1980 and 2005 revealed that intellectual property index and the number of patents can better reflect the comprehensive strength of regional innovation, and when the endogenous variables remain unchanged, improving the two substitute indexes can significantly promote economic growth. Gerald (2007) showed that patent intensity, i.e., per capita invention rate, is positively related to the density of employment in the highly urbanized portion of Mas [25]. All else equal, a city with twice the employment density (jobs per square mile) of another city will exhibit a patent intensity (patents per capita) that is $20 \%$ higher. Patent intensity is the highest at an employment density of about 2200 jobs per square mile. A city with a more competitive market structure or one that is not too large (a population less than 1 million) will also show a higher patent intensity. Liu et al. (2019) analyzed the spatial dynamics of intercity technology transfer networks in China's three urban agglomerations based on patent right transaction data in 2008-2015 [26]. They found that Beijing, Shanghai, and Shenzhen are emerging as hubs in the three urban agglomerations. The spatial distributions of degree and weighted degree are significantly heterogeneous and hierarchical. The Beijing-Tianjin-Hebei agglomeration is organized in a tree network, the Yangtze River Delta features a polycentric network and the Pearl River Delta has multi-star characteristics.

The second aspect is the spatial pattern and relevance of innovation. Breschi (2000) used the patent data of the European Patent Office in 1978-1991 for regression analysis, and found that there are systematic differences in the spatial pattern of innovation among different technological classes, while there is a significant similarity between countries in the spatial pattern of innovation of each technological class [27]. Moreno (2005) explored the spatial distribution of innovation activities and the role of technology spillovers in the process of knowledge creation and diffusion in 175 regions of the European Union, and found that the distribution of innovation activities shows strong center-periphery characteristics [28]. Specifically, innovation activities are concentrated in the northern and central parts of Europe, while few or no innovation activities occur in southern Europe. However, as time goes by, this spatial pattern tends to become insignificant. Keller (2002) and Ron (2005) studied the spatial relevance of innovation activities, and found that technology spillover effect weakens as the geographic distance increases [29,30]. Fornahl and Brenner (2009) applied different concentration measures to patent data for Germanregions, and analyzed 43 technological fields separately to identify which of these technologies tend to cluster in geographic space [31]. 
Capello and Lenzi (2014) studied the static and dynamic agglomeration effects of European innovation activities, and found the higher the concentration of innovation activities, the higher the productivity of regional R\&D [32]. Balland and Rigby (2017) analyzed more than two million patent records from the US Patent and Trademark Office to identify the technological structure of US metropolitan areas in terms of the patent classes in which they are most active between 1975 and 2010 [33]. They found that knowledge complexity is unevenly distributed across the US and cities with the most complex technological structures are not necessarily those with the highest rates of patenting.

The third aspect is regional innovation and the influencing factors of innovation ability. Miguelez and Moreno (2018) analyzed the relevance of variety in the case of local knowledge as well as in the case of the knowledge coming from other regions [34]. At the local level, it shows that while related variety is conducive to regional innovation, unrelated variety does play a role, too, when it comes to radical innovations. Conversely, it also shows that the higher the impact of external knowledge flows, the higher the similarity between these flows and the extant local knowledge base. Paula et al. (2018) used a longitudinal database of innovative publicly traded European companies between 1991 and 2008 to analyze the effect of the interplay between regional and sectoral dimensions in the firm-level R\&D-productivity link [35]. Yueh (2009) studied the factors that influence China's innovation ability after the reform and opening up in 1979, and found that there are significant differences in the influencing factors of innovation among various regions of China [36]. In spite of this, Yueh found that the input of R\&D personnel remains an important determinant of innovation output, and increase in per capita GDP tends to enhance innovation. Besides, Yueh found that foreign investment has a significant negative correlation with innovation ability in coastal areas. Varga (2014) analyzed the relationship between innovation and economic growth from a theoretical perspective, and used empirical data from 262 regions of the EU on knowledge, innovation and economic growth models [37]. The results show that the level of economic development in knowledge-intensive regions is obviously higher than that in labor-intensive regions. Therefore, innovation is a key driver of economic growth, and in turn economic growth further promotes the output of innovation. Piperopoulos (2018) studied the impact of Outward Foreign Direct Investment (OFDI) on emerging market countries and developed countries, and found that OFDI has a significant positive impact on China's emerging markets [38].

The four aspect is innovation and geographical spillovers. Audretsch and Feldman (1996) examined the spatial distribution of innovative capacity as well as the geographic concentration of production. Their results suggest that the propensity for innovative activity to cluster is more attributable to the role of knowledge spillovers and not merely the geographic concentration of production [39]. Agusti et al. (2018) analyzed different typologies of innovation processes carried out in several geographical areas and highlighted heterogeneities of these processes, after focusing on several determinants in innovation [40]. Empirical results indicate the positive role of geographical spillovers and the importance of accurate matching among firms, in industry and with regard to regional characteristics, in order to ensure the generation of knowledge and innovation. Angela and Sara (2018) examined the influence of open-innovation strategies and knowledge spillovers on innovative performance based on a large sample of Spanish manufacturing firms during 1998-2013 [41]. Although most open-innovation strategies positively influence innovation, some differences are found depending on the innovation strategy adopted: technological collaboration with universities, providers, and external research and development (R\&D) institutes have a positive effect, while collaborations with customers and competitors are not significant.

Due to its advantageous geographical location, efficient transportation system, good innovation environment and reasonable industrial structure, Guangdong-Hong Kong-Macao greater bay area, as well as its remarkable economic characteristics have become the research hotspots at home and abroad. Sujita and Rodgers (2018) assessed the degree of regional integration in the Guangdong-Hong Kong-Macau greater bay area [42]. They presented the future spatial development plans and regional cooperation initiatives for the cities in the greater bay area, and proposed strategies on how Hong Kong can more effectively integrate into the greater bay area at 
the economic, social and political levels. Eddie (2018) used network analysis to examine the factors affecting regional integration and spatial linkages in the Guangdong-Hong Kong-Macau greater bay area [43]. The study found that the important contribution of the formation and success of the Guangdong-Hong Kong-Macau greater bay area is the increase in transportation infrastructure and carrying capacity. Especially, high-speed railways are a key factor in promoting free movement, and strong spatial and transport connections have greatly contributed to regional integration. $\mathrm{Li}$ (2018) proposed that more consideration of social concerns in Guangdong province and a proper level of public participation in Hong Kong are necessary in order to avoid excessive interruptions to the pace of project procurement, and Macao may have to experience a relatively slow development of construction in order to balance the social/environmental requirements that are involved [44]. In spite of these research literatures on the Guangdong-Hong Kong-Macao greater bay area, there is little research on the innovation aspect of this region. Therefore, this paper aims to study the spatial pattern characteristics of the innovation output of the Guangdong-Hong Kong-Macao greater bay area and its influencing factors.

In sum, innovation is the decisive factor of the core competitiveness and sustainability of development of industry. The accumulation of innovative elements in Guangdong-Hong Kong-Macao greater bay area is the key to building an innovative bay area and enhancing regional competitiveness. The innovative elements include technological resources, financial resources, as well as creative entrepreneurs, engineers and other talents. The agglomeration and integration of these innovative elements have effectively promoted the emergence of innovative activities. At the same time, various industrial clusters have been formed in the Guangdong-Hong Kong-Macao greater bay area, and the geographic concentration of industries has led to an increase in scale returns and further promoted the marketization and industrialization of innovation results. As a result, an efficient and innovative system of "R\&D-production-manufacture-sale-re-development" is formed and greatly promotes the prosperity and development of innovation economy in Guangdong-Hong Kong-Macao greater bay area.

Therefore, this paper took the innovation output of Guangdong-Hong Kong-Macao greater bay area as the research object, analyzed the basic environment of innovation in the study region, and investigated the spatial pattern of innovative output in the study region. In addition, by using panel data from 2000 to 2016 in the study region, this paper empirically studied the impact of various factors on the innovation output of Guangdong-Hong Kong-Macao greater bay area. Further, policy recommendations were proposed to improve the innovation capability of the study region.

\section{The Basic Environment for Innovation in Guangdong-Hong Kong-Macao Greater Bay Area}

The development of Guangdong-Hong Kong-Macao greater bay area has experienced several stages including port agglomeration, industrial agglomeration, service industry agglomeration and innovative resource agglomeration. This region shows typical economic characteristics of a bay area and export-oriented economic characteristics. It has favorable conditions for innovation activities, and these conditions include large-scale port cluster, characteristic industrial cluster and developed urban cluster. In 2017, the number of high-tech enterprises in Guangdong Province ranked first in China, reaching 19,857, among which 95.1\% were in the nine cities of the Pearl River Delta. In 2017, the population in Guangdong-Hong Kong-Macao greater bay area accounted for less than 5\% of China's total population, while the number of patent grants accounted for $17.6 \%$ of all patent grants of the nation. Notably, the number of PCT international patent applications in this region accounted for $56 \%$ of those in China. Guangdong-Hong Kong-Macao greater bay area has become a place where high-tech industries and creative talents concentrate, a place that has high scientific and technological strength, and a place that is an important hub of "One Belt, One Road". In order to more clearly reflect the objective conditions for innovation activities in Guangdong-Hong Kong-Macao greater bay area, we analyzed and summarized the basic environment for innovation and development in this region from three aspects including location and port conditions, economic and financial support, and urban division of labor and industrial system. 
The advantageous location and port clusters of the study region provide favorable conditions for its innovative development. It is located on the southeast coast of China, mainly in the Pearl River Bay area and also in Dapeng Bay area, Daya Bay area and other peripheral bay areas. It covers an area of $56,500 \mathrm{~km}^{2}$, accounting for $1.04 \%$ of China's land area, and consists of 9 cities in Guangdong Province (Guangzhou, Shenzhen, Zhuhai, Dongguan, Foshan, Jiangmen, Zhaoqing, Zhongshan, and Huizhou) and two special administrative regions, including Hong Kong and Macao. Therefore, it is referred to as " $9+2$ ". The unified planning and coordinated development of the port clusters enhances the overall economic competitiveness of the region. It has the largest seaport group and airport group in the world, mainly composed of three world-class ports in Guangzhou, Shenzhen and Hong Kong, respectively, and five major local ports in Zhuhai, Zhanjiang, Dongguan, Huizhou and Shantou, respectively. The annual throughput of containers of the seaport group is 69.647 million TEU, which is 4.5 times the total container throughput of the world's three major bays including New York's Greater Bay area, San Francisco's Greater Bay area and Tokyo's Greater Bay area. Gradually, a well-functioned port system with the three hub ports as the mainstay and the five local ports as two wings is formed.

Strong economic strength and sound financial system are the solid foundation for scientific and technological innovation and development. Guangdong-Hong Kong-Macao greater bay area is characterized by strong economic strength, which is reflected in the large number of Fortune 500 companies and innovative enterprises in this region. It plays an important role in global economic growth and is an important engine for China's economic growth. According to the economic and population statistics of the study region (Table 1), its total GDP and per capita GDP have been increasing year by year, finally leading to that about $5 \%$ of the country's population has created more than $12 \%$ of the total economic output. The growth rate of GDP remains higher than $8 \%$ except for a few years. In 2016, the GDP of the study region reached 1.4 trillion US dollars, accounting for $12.53 \%$ of the country's total GDP. The scale of its economy is equivalent to that of Korea, the world's 11th largest economy (the total GDP is 1.4 trillion US dollars). In 2016, the per capita GDP of the study region was US\$17,600, which was 2.16 times of China's per capita GDP. The growth rate of GDP of the study region was $9.02 \%$ in 2016, which was 2.19 times of that of the Tokyo greater bay area, 2.26 times of that of the New York greater bay area, and 2.93 times of that of the San Francisco greater bay area. Note that the proportion of the GDP of the study region in that of the country has been declining year by year, mainly because the proportion of the GDP of Hong Kong and Macao in the national GDP has been declining. In addition, the sound financial industry of the study region strongly supports its innovation and development. The study region is a gathering place for internationally renowned financial institutions, including Hong Kong-owned stock exchanges, Shenzhen Stock Exchange, Shenzhen Venture Capital Center, Guangzhou Commercial Bank Center, Macau and Zhuhai Asset Management Center, and the Nansha Commodity Futures Exchange. According to the 24th Global Financial Centers Index (GFCI24) issued by the UK Think Tank Z/YEN Group in 2018, Shenzhen's financial industry is highly competitive in terms of business environment, financial system, infrastructure, human capital, and city reputation, and it ranked 12th in the world and ranked 3rd in Hong Kong's financial industry competitiveness. In recent years, the deep integration of the financial industries in Hong Kong and Shenzhen has driven the rapid development of financial industries in other cities in the study region and enhanced the overall competitiveness of the financial industry in the study region.

Table 1. Economic and population statistics of Guangdong-Hong Kong-Macao greater bay area.

\begin{tabular}{ccccccc}
\hline $\begin{array}{c}\text { GDP } \\
\text { (Trillion } \\
\text { US } \\
\text { dollar) }\end{array}$ & $\begin{array}{c}\text { Accounting } \\
\text { for China's } \\
\text { GDP (\%) }\end{array}$ & $\begin{array}{c}\text { GDP } \\
\text { growth } \\
\text { rate (\%) }\end{array}$ & $\begin{array}{c}\text { Per capita } \\
\text { GDP } \\
\text { (Thousand } \\
\text { US dollars / } \\
\text { person) }\end{array}$ & $\begin{array}{c}\text { Resident } \\
\text { population } \\
\text { at the end of } \\
\text { the year } \\
\text { (Thousand) }\end{array}$ & $\begin{array}{c}\text { Accounting } \\
\text { for China's } \\
\text { population } \\
\text { (\%) }\end{array}$ \\
\hline 2016 & 1.40 & 12.53 & 9.02 & 17.6 & 79915.3 & 5.78 \\
2015 & 1.37 & 12.41 & 8.02 & 17.6 & 78078.0 & 5.68 \\
\hline
\end{tabular}




\begin{tabular}{lllllll}
2014 & 1.29 & 12.29 & 8.53 & 19.7 & 65522.9 & 4.79 \\
2013 & 1.18 & 12.25 & 9.18 & 18.1 & 64971.2 & 4.77 \\
2012 & 1.06 & 12.36 & 8.18 & 16.4 & 64570.1 & 4.77 \\
2011 & 0.96 & 12.62 & 12.67 & 14.9 & 64132.3 & 4.76 \\
2010 & 0.81 & 13.27 & 13.72 & 12.7 & 63756.6 & 4.75 \\
2009 & 0.71 & 13.81 & 3.50 & 11.5 & 61147.0 & 4.58 \\
2008 & 0.67 & 14.58 & 9.62 & 11.4 & 58891.8 & 4.43 \\
2007 & 0.56 & 15.72 & 11.83 & 9.9 & 56268.8 & 4.26 \\
2006 & 0.48 & 17.31 & 11.80 & 8.8 & 54173.3 & 4.12 \\
2005 & 0.41 & 18.14 & 15.17 & 7.9 & 52793.5 & 4.04 \\
2004 & 0.36 & 18.23 & 14.21 & 6.8 & 52425.5 & 4.03 \\
2003 & 0.31 & 18.80 & 7.86 & 6.0 & 51846.7 & 4.01 \\
2002 & 0.29 & 19.68 & 3.66 & 5.6 & 51313.1 & 3.99 \\
2001 & 0.28 & 20.84 & -0.25 & 5.8 & 48019.3 & 3.76 \\
2000 & 0.28 & 23.10 & 24.19 & 5.6 & 50040.8 & 3.95 \\
\hline
\end{tabular}

Data sources: Guangdong statistical yearbooks; Hong Kong statistical yearbooks; Macao statistical yearbooks.

Rational and orderly urban division of labor and modern industrial system provide a solid guarantee for the innovation and development of the study region. The cities of the study region are all characterized by a rational division of labor and coordinated development, which is based on the polycentric and hierarchical spatial strategy that is adopted in this region. Hong Kong is the world's third largest financial center, the world's most influential trading center, and a modern service industry center. Shenzhen is an international scientific and technological innovation center, a global high-end financial industry complex, and a domestic high-tech industrial center. Guangzhou is a major hub for international shipping, aviation, electronic information technology, advanced manufacturing and biomedical health industries. Macau is a cultural exchange center dominated by entertainment and tourism and is the world's largest gaming center. Dongguan, Foshan and Zhuhai are the world's factories, with complete manufacturing industry system and high degree of industrial clustering. The industry in these three regions has gradually transformed from labor-intensive manufacturing industry to advanced and high-tech manufacturing industry. Huizhou is a place with extensive transformation of innovation results, Zhongshan is a world-class advanced manufacturing base, and Jiangmen and Zhaoqing are the hub cities connecting the outside world and the study region. Production capacity can be transferred from Guangzhou and Shenzhen to these regions. In addition, the study region has a highly developed and well-established industrial system, providing space and opportunities for the development of new and innovative industries including strategic emerging industries, advanced manufacturing industries, and modern service industries. Industrialization and informationization are highly integrated, and resources such as finance, trade and industry are efficiently allocated. This region is the main supplier of industrial goods along the "Maritime Silk Road". The modern industrial system with international competitiveness, including the new generation information technology, biotechnology, high-end equipment manufacturing, emerging materials and other industries, will provide new impetus and guarantee for the sustainable development of economy and innovation activities in the study region.

\section{Identification of Innovation Patterns in Guangdong-Hong Kong-Macao greater bay area}

Above analysis reveals that Guangdong-Hong Kong-Macao greater bay area has advantageous location, port clusters, strong economic strength, developed financial system, rational and orderly urban division of labor and modern industrial system. These advantages provide a continuous driving force for the innovation activities in the study region. Since there is significant spatial difference in the resource endowment and factor flow in the study region, the division of labor presents a specific spatial pattern and as a kind of advanced economic activity, innovation also presents a certain degree of spatial concentration and spatial dependence. Therefore, in order to fully 
reveal the basic characteristics of innovation activities in the study region, it is necessary to analyze their spatial distribution in this region.

\subsection{Spatial Differences in Innovation Activities in Guangdong-Hong Kong-Macao greater bay area}

Innovation activity is a complex process that includes the generation of ideas, product development, design, production, etc. It is difficult to accurately measure innovation activities. Scholars usually use patents, scientific papers, R\&D investment, as well as R\&D personnel as indicators for innovation activity measurement $[45,46]$. Among them, patents are a commonly used indicator of regional innovation capability and output. This is because patents are closely related to business applications, enable easy access to data, and can comprehensively reflect the innovation and invention activities in a region. Correlation analysis also shows that there is a very close relationship between patents and innovation activities. Due to the high correlation between the number of patent applications and the amount of patents granted, the spatial distribution characteristics of innovation activities measured by using the two are not much different. This paper analyzed the spatial pattern of innovation activities in the study region in 2000-2016 by using the amount of patents granted as an indicator.

First, we comparatively analyzed the amount of patents granted in various areas of the study region. The results show that the amount of patents granted in Shenzhen was the largest, reaching 75,043 and accounting for $32.1 \%$ of the total patents granted in the study region. The amount of patents granted in Guangzhou ranked second and reached 48,313. The amount of patents granted was less than 10,000 in Zhuhai, Jiangmen, Zhaoqing, Huizhou, Hong Kong and Macao, among which Macao had the least amount of patents granted (only 179, which was less than $2.4 \%$ of that in Shenzhen). Clearly, there is significant spatial variation in innovation activities in the study region, which can be attributed to the spatial variation in factor endowments, innovation opportunities, innovation inputs, economic levels, and institutional conditions in the study region. At the same time, considering the Matthew effect of innovation, an area with strong innovation capability will gain a strong competitive advantage through innovation, which further promotes the emergence of innovation activities and the enhancement of innovation capability, thus the spatial pattern of innovation activities is continuously strengthened.

Second, we analyzed the evolution of the spatial pattern of innovation output in the study region in 2000-2016. The results (Fig. 1)2 show that high innovation outputs were mainly in the central part of the study region, and the innovation output presented an overall spatial pattern of "center-periphery". Along with the continuously increasing number of innovations in the study region, the center cities of high innovation output changed from Guangzhou and Foshan, to Shenzhen and Foshan, to Shenzhen and Dongguan, and to Shenzhen and Guangzhou. Shenzhen and Guangzhou have gradually become two centers of high innovation output in the study region.

Finally, we measured the spatial differences in the innovation activities among cities in the study region. Lim (2003) [47] used the US patent grants from 1990 to 1999 to calculate the location Gini-coefficient and the Moran's I index. The study found that the US innovation activities are highly concentrated in a few metropolitan areas, and there is a clear positive spatial autocorrelation.

We calculated the absolute Gini coefficient of the granted patent amount in the study region. The calculation formula is as follows.

$$
G=\frac{1}{2 n^{2} \bar{x}} \sum_{i=1}^{n} \sum_{j=1}^{n}\left|x_{i}-x_{j}\right|
$$

where $G$ is the absolute Gini-coefficient of the measured innovation output; $x_{i}$ and $x_{j}$ are the shares of innovation output of area $i$ and area $j$ in the innovation output of the study region, respectively; $\bar{x}$ is the average regional innovation output. The range of $G$ is $(0, n-1 / n)$. The

\footnotetext{
${ }^{2}$ Source of data: China Intellectual Property Office; Guangdong Provincial Intellectual Property Office.
} 
greater the value of $G$, the greater the spatial difference in innovation activities. The results (Fig. 2) ${ }^{3}$ reveal that from 2000 to 2016, the Gini coefficient of innovation in the study region fluctuated between 0.4 and 0.6 , which indicates that there is significant spatial difference in the innovation activities among the various areas of the study region.

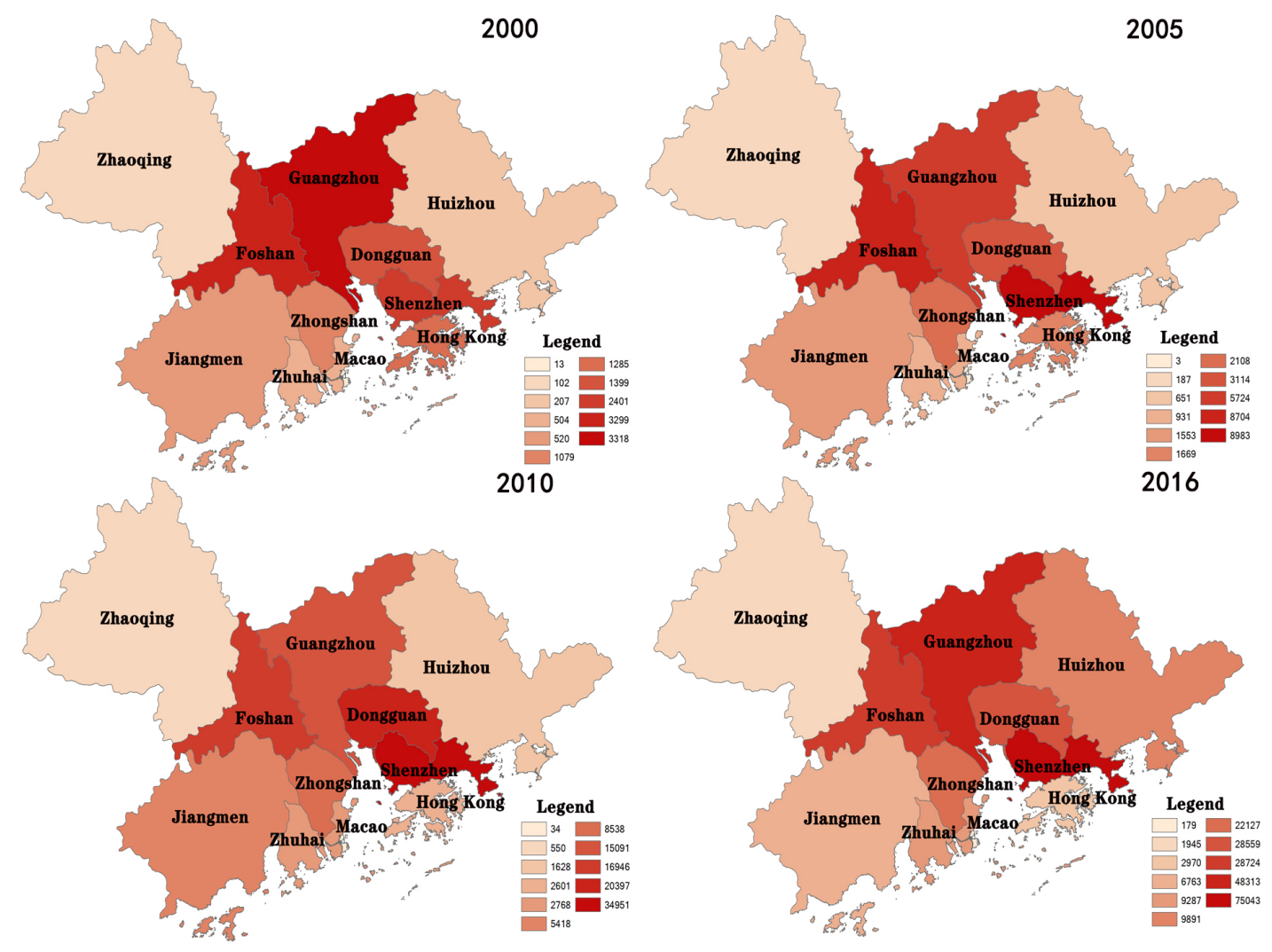

Figure 1. Spatial distribution of patents granted in Guangdong-Hong Kong-Macao greater bay area.

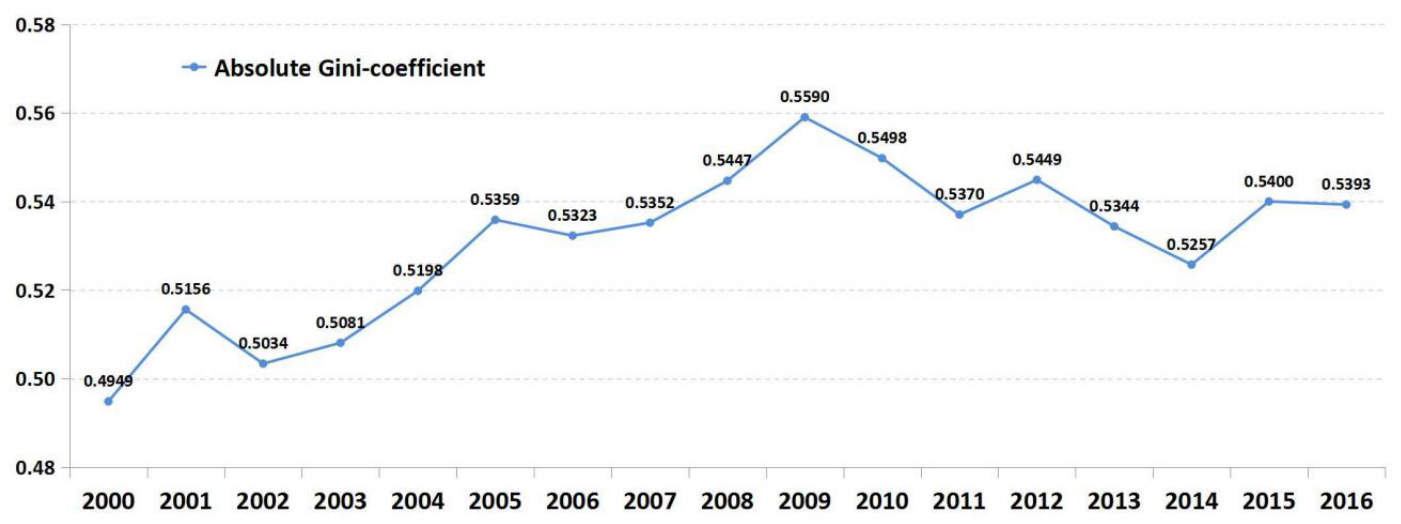

Figure 2. Time variation of absolute Gini Coefficient of innovation in Guangdong-Hong Kong-Macao greater bay area

\subsection{Typical Characteristics of the Innovation Pattern in Guangdong-Hong Kong-Macao Greater Bay Area}

Based on above analysis, the spatial pattern characteristics of innovation activities in the study region were further analyzed. The primacy ratio index proposed by Jefferson (1939) was used here to analyze innovation activities [48]. The primacy ratio index measures the ratio of the primacy area

\footnotetext{
${ }^{3}$ Source of data: China Intellectual Property Office; Guangdong Provincial Intellectual Property Office.
} 
to other areas. Therefore, the contrast between the center and the periphery can be quantitatively depicted. It is one of the important indicators for measuring the characteristics of spatial distribution pattern. The formula for calculating the primacy ratio index is as follows.

$$
S=Y_{1} / Y_{2}
$$

where $S$ is the primacy ratio index, $Y_{1}$ is the amount of innovation activities in the primacy region, and $Y_{2}$ is the amount of innovation activities in the secondary region. The results (Fig. 3) reveal that from 2000 to 2016, the primacy ratio index of innovation activities in the study region fluctuated between 1 and 3 and presented an overall upward trend, indicating that the innovation activities were not highly concentrated in a single central city in the study region. Taking 2016 as an example, as the primacy city for innovation activities in the study region, Shenzhen presented 75,043 granted patents, accounting for $32.1 \%$ of the total patents granted in the study region.

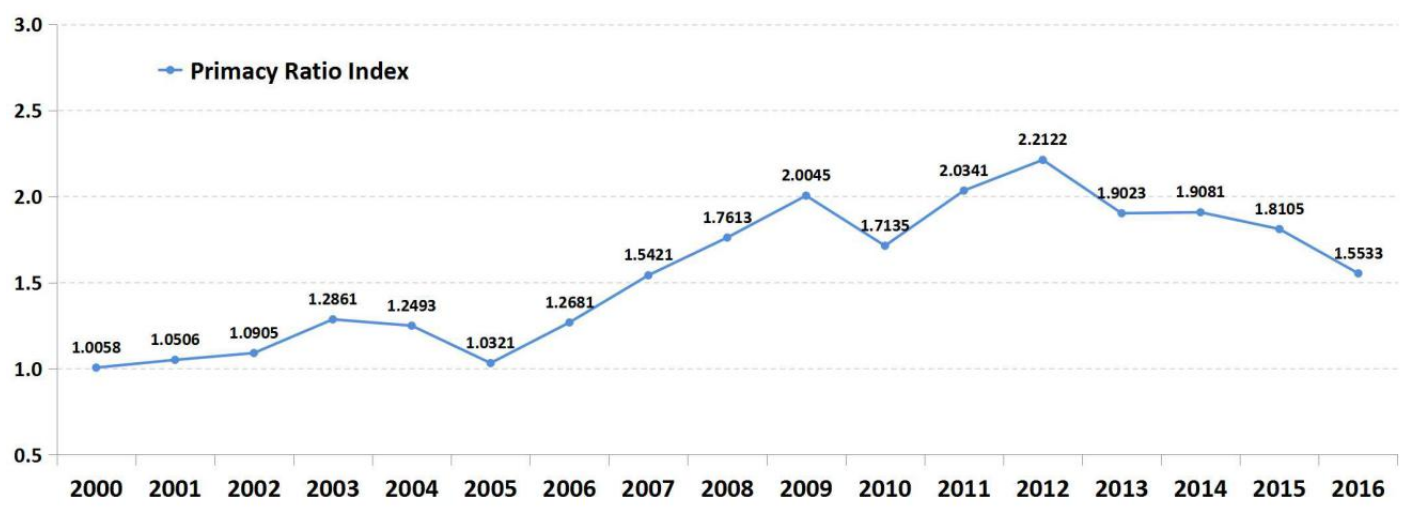

Figure 3. Primacy ratio index of innovation in Guangdong-Hong Kong-Macao greater bay area.

Further, we used concentration index to analyze the geographic concentration of innovation activities in the study region. The concentration index is calculated as follows.

$$
C R_{n}=\sum_{i=1}^{n} S_{i}
$$

where $C R_{n}$ is the concentration index of the first n-bit region and $S_{i}$ is the ratio of the value of $i$ th sample to that of the total region. The results are shown in Fig. 4. When $n=2$, the concentration index of the study region exceeded $50 \%$ after 2004 . When $n=4$, the innovation outputs were mainly concentrated in Shenzhen, Guangzhou, Foshan and Dongguan, and the total innovation outputs of the four cities accounted for about $80 \%$ of the total innovation output of the study region. Since 2012, the innovation output of some primary regions has supported the development of innovation activities across the whole study region. Shenzhen and Guangzhou are as the centers of innovation and rely on their rich innovation resources and knowledge spillover effect to drive the continuous improvement of the innovation output level of small cities such as Foshan and Dongguan. 


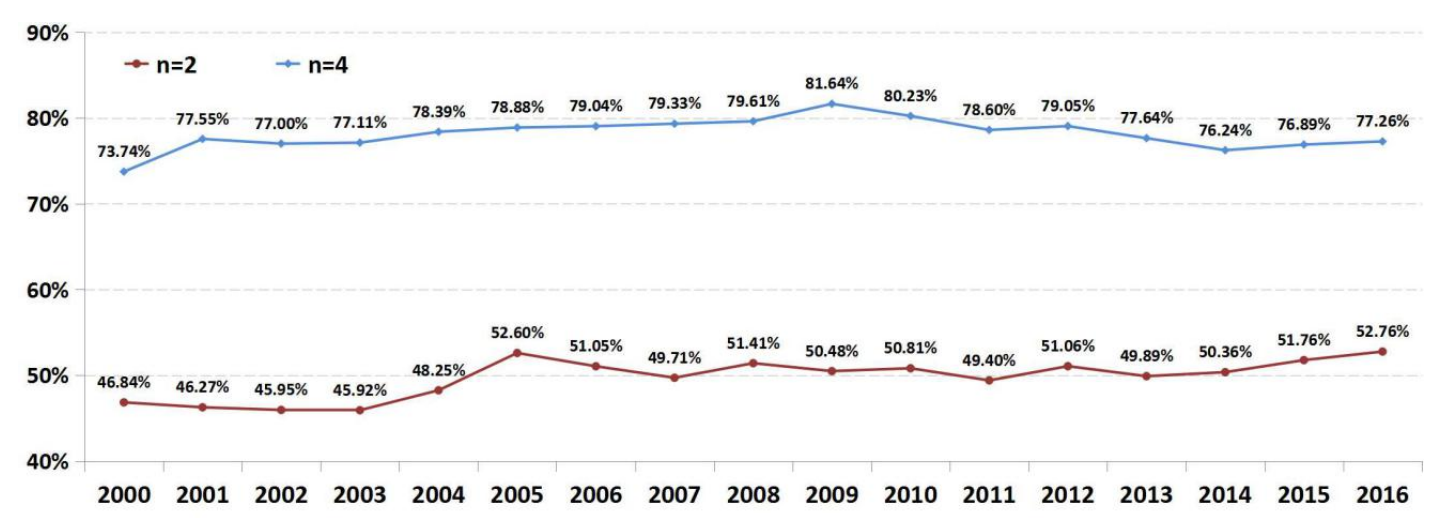

Figure 4. Concentration Index of innovation in Guangdong-Hong Kong-Macao greater bay area.

In addition, innovation activities not only have the characteristics of spatial agglomeration, but also have spatial relevance and spatial spillover effect. In order to explain the relationship between innovation activities in different areas of the study region, it is necessary to measure the spatial correlation of innovation activities in this region. Yang (2016) used Moran's I index to evaluate the spatial correlation and dependence of innovation output in the study region [49]. The specific calculation formula is as follows.

$$
\text { Moran's } \mathrm{I}=\frac{\sum_{i=1}^{n} \sum_{j=1}^{n} W_{i j}\left(X_{i}-\bar{X}\right)\left(X_{j}-\bar{X}\right)}{S^{2} \sum_{i=1}^{n} \sum_{j=1}^{n} W_{i j}}
$$

where $X_{i}$ is the observed value of the $i$ th region, $n$ is the total number of regions, $S^{2}$ is the standard deviation of the values of $n$ regions, and $W_{i j}$ is the spatial weight matrix. In this paper, the Moran's I index was calculated for the patent grant amount and the patent grant amount per 100,000 people, and the calculation results are shown in Table 2. From 2000 to 2016, the overall Moran's I indexes of the two indicators in Guangdong-Hong Kong-Macau greater bay area were lower than 0 , and the $\mathrm{P}$ values did not pass the $10 \%$ significance test. Here, the prefecture-level cities were taken as the geographical units for research and at this spatial scale the innovation activities do not show obvious spatial dependence. In the study region, not every city has a strong innovation ability. The study region has a long-term developed spatial structure of innovation activities with Shenzhen and Guangzhou as the dual centers. Due to polarization effect, the spillover effects of the two centers are relatively weak, which leads to the insignificant global Moran's I index of innovation in Guangdong-Hong Kong-Macau greater bay area.

Table 2. Global Moran's I Index of Innovation Output in Guangdong-Hong Kong-Macau greater bay area.

\begin{tabular}{lcccccc}
\hline & Moran's I & P-Value & Z-Value & Moran's I & P-Value & Z-Value \\
\hline $\mathbf{2 0 0 0}$ & -0.1532 & 0.8291 & -0.2158 & -0.1298 & 0.8246 & -0.2217 \\
$\mathbf{2 0 0 1}$ & -0.2192 & 0.6321 & -0.4786 & -0.1646 & 0.6278 & -0.4848 \\
$\mathbf{2 0 0 2}$ & -0.2168 & 0.6399 & -0.4678 & -0.1984 & 0.4636 & -0.7329 \\
$\mathbf{2 0 0 3}$ & -0.2092 & 0.6571 & -0.4439 & -0.1429 & 0.7403 & -0.3315 \\
$\mathbf{2 0 0 4}$ & -0.2329 & 0.5861 & -0.5445 & -0.1870 & 0.5197 & -0.6438 \\
$\mathbf{2 0 0 5}$ & -0.3065 & 0.301 & -0.8578 & -0.1882 & 0.5024 & -0.6707
\end{tabular}




\begin{tabular}{lcccccc}
$\mathbf{2 0 0 6}$ & -0.2871 & 0.4306 & -0.7882 & -0.2556 & 0.2490 & -1.1527 \\
$\mathbf{2 0 0 7}$ & -0.2686 & 0.4656 & -0.7296 & -0.2772 & 0.1943 & -1.2981 \\
$\mathbf{2 0 0 8}$ & -0.2646 & 0.449 & -0.7571 & -0.2794 & 0.1904 & -1.3094 \\
$\mathbf{2 0 0 9}$ & -0.2125 & 0.6042 & -0.5184 & -0.2878 & 0.1657 & -1.3862 \\
$\mathbf{2 0 1 0}$ & -0.1879 & 0.6943 & -0.3901 & -0.2736 & 0.2058 & -1.2651 \\
$\mathbf{2 0 1 1}$ & -0.199 & 0.6412 & -0.466 & -0.2706 & 0.2105 & -1.2521 \\
$\mathbf{2 0 1 2}$ & -0.2117 & 0.5766 & -0.5583 & -0.2894 & 0.1611 & -1.4013 \\
$\mathbf{2 0 1 3}$ & -0.1949 & 0.6572 & -0.4438 & -0.2405 & 0.3010 & -1.0344 \\
$\mathbf{2 0 1 4}$ & -0.2354 & 0.5138 & -0.6529 & -0.2612 & 0.2373 & -1.1819 \\
$\mathbf{2 0 1 5}$ & -0.2245 & 0.5547 & -0.5907 & -0.2203 & 0.3715 & -0.8936 \\
$\mathbf{2 0 1 6}$ & -0.2356 & 0.5365 & -0.6181 & -0.2456 & 0.2873 & -1.0640 \\
\hline
\end{tabular}

Data source: GIS 10.3 software calculates that 1 and 2 are the measurement results of the patent grant amount and the patent grant amount per 100,000, respectively.

In sum, the innovation pattern of the study region presents a multi-center network structure with Shenzhen and Guangzhou as dual centers and engines of innovation, and Dongguan and Foshan as the main regions of innovation. Overall, the innovation activities generally show a spatial pattern of "center-periphery". Innovation activities have certain dependence on knowledge, talents, culture and institutions, and the spatial aggregation of these innovative elements is obvious. Their accumulation can facilitate communication and mutual learning between subjects, and promote technological innovation, progress and diffusion. On the other hand, the innovation gap between cities in the study region continues to expand due to the spatial accumulation of innovative elements. Nonetheless, innovative elements such as knowledge and technology will overflow from the primary city with high level of innovation to neighboring cities with low level of innovation, thus the level of innovation in the neighboring cities will be significantly enhanced. On the basis of the division of labor and cooperation among cities in the study region, the transformation and diffusion of innovation results have been accelerating, and the process of regional economic integration driven by innovation and development has been promoted.

\section{Analysis of Influencing Factors of Innovation Output in Guangdong-Hong Kong-Macao Greater Bay Area}

\subsection{Model Construction and Variable Selection}

Innovation, as a high-level economic activity, belongs to the category of knowledge economy. This paper draws on the knowledge production function proposed by Criliches (1998) to analyze the main factors affecting the innovation output of Guangdong-Hong Kong-Macao greater bay area [50]. Specifically, the knowledge production function formula is as follows.

$$
Y=A K^{\alpha} L^{\beta} Z^{\gamma}
$$

where $Y$ is the innovation output, $K$ is the innovation investment, $L$ is the number of innovators, $Z$ is other economic factor that affects innovation output, and $\alpha, \beta$ and $\gamma$ are corresponding elastic coefficients. By logarithmically transforming formula (5), we can obtain an empirical model as follows (Considering the availability of data and the stability of the model, this paper did not include Macao in the analysis of the panel data model. The data come from the China Intellectual Property Office, Guangdong Statistical Yearbook, and Hong Kong Statistical Yearbook.)

$$
\ln Y_{i t}=\alpha+\beta_{1} \ln K_{i t}+\beta_{2} \ln L_{i t}+\beta_{3} \ln Z_{i t}+\mu_{i t}
$$

Here, we chose the number of patents granted to measure innovation output $(Y)$, total $R \& D$ expenditures to measure innovation investment $(K)$, and number of R\&D personnel to measure the 
number of innovators $(L)$. Total R\&D expenditures include government R\&D funding, R\&D funding for universities and research institutions, and corporate R\&D funding. At the same time, we chose economic development level, industrial structure and foreign direct investment as other influencing factors of innovation output. Kaldor (1975) proposed that invisible knowledge is geographically sticky, the benefits of technological advances usually remain local, and the growth of regional economy and the improvement of innovation level are related in a causal cycle [51]. Du (2018) put forward that the dominant tendencies of innovation patents in different industries are different, and with the upgrading of regional industrial structure and the deepening of industrial division of labor, the tertiary industry has often become the main driving force for regional innovation and development [52]. Piperopoulos (2018) thought that foreign direct investment can help regions and enterprises to integrate innovation resources at home and abroad through conceptual learning, thereby enhancing innovation performance. He proposed that OFDI is a key mechanism for learning and developing innovative skills in backward regions around the world [38]. Therefore, per capita GDP (pgdp) was selected here to measure regional economic development level, tertiary industry ratio (ser) was selected to measure industrial structure, and per capita foreign direct investment (pfdi) was selected to measure foreign direct investment.

\subsection{Descriptive statistics and correlation analysis of variables}

This paper took 10 prefecture-level cities in the Guangdong-Hong Kong-Macao greater bay area as research objects. The time span of data was from 2000 to 2016, and the patent grant data and economic data came from the China Intellectual Property Office, Guangdong Statistical Yearbook, Hong Kong Statistical Yearbook and Macao Statistical Yearbook. The amount of patents granted was as the explained variable $(\mathrm{Y})$. The explanatory variables included total R\&D expenditure (K), the number of R\&D personnel (L), per capita GDP (pgdp), tertiary industry ratio (ser), and per capita foreign direct investment (pfdi).

Table 3. Descriptive statistics of variables.

\begin{tabular}{cccccc}
\hline Variable & Minimum & Maximum & The average & $\begin{array}{c}\text { The standard } \\
\text { deviation }\end{array}$ & $\begin{array}{c}\text { Number of } \\
\text { samples }\end{array}$ \\
\hline $\ln Y$ & 4.41884 & 11.22582 & 8.186621 & 1.455745 & 170 \\
InK & 19.11872 & 25.05404 & 21.94014 & 1.359694 & 170 \\
InL & 7.18007 & 12.21194 & 9.751243 & 1.077398 & 170 \\
Inpgdp & 8.9122 & 12.6298 & 10.88969 & 0.8113559 & 170 \\
ser & 27.7 & 93.1 & 48.88969 & 16.66538 & 170 \\
Inpfdi & 6.401061 & 12.66495 & 7.936306 & 1.13706 & 170 \\
\hline
\end{tabular}

Based on the descriptive statistics of the variables (Table 3), we found that there exists large difference in the individual values of the variables. For example, the minimum value of innovation output was 4.42 and the maximum value was 11.23, which is 2.5 times the minimum value. The minimum tertiary industry ratio was $27.7 \%$ and the maximum ratio was $93.1 \%$, which is 3.4 times the minimum ratio. In Guangdong-Hong Kong-Macao greater bay area, the economic development levels of Dongguan, Foshan, Zhuhai, Jiangmen, Zhaoqing, Huizhou and Zhongshan are relatively lower than those of developed regions such as Hong Kong, Guangzhou and Shenzhen. Therefore, it is reasonable that there exists great difference in the tertiary industry ratio between different cities.

In order to better examine the relationship between variables, the correlations between the explained variable and all explanatory variables were analyzed to obtain the correlation coefficients (Table 4). 
Table 4. Coefficients of correlation between variables.

\begin{tabular}{ccccccc}
\hline & $\operatorname{lnY}$ & Inrde & Inrdp & Inpgdp & ser & Infdi \\
\hline $\operatorname{lnY}$ & 1.0000 & & & & & \\
Inrde & 0.8280 & 1.0000 & & & & \\
Inrdp & 0.8824 & 0.9333 & 1.0000 & & & \\
Inpgdp & 0.6173 & 0.8534 & 0.7051 & 1.0000 & & \\
ser & 0.1543 & 0.5191 & 0.3274 & 0.7094 & 1.0000 & 1.0000 \\
\hline Infdi & -0.0979 & 0.3360 & 0.0854 & 0.6173 & 0.8197 & \\
\hline
\end{tabular}

Table 4 shows that the patent grant amount was positively correlated with the tertiary industry ratio (ser), per capita GDP (lnpgdp), R\&D expenditure (lnrde), and the number of R\&D personnel (lnrdp), and the correlation coefficients were $0.1543,0.6173,0.8280$, and 0.8824 , respectively. The results indicate that innovation input (fund and personnel), economic development level and industrial structure have strong positive influence on innovation output. Notably, patent grant amount was negatively correlated with per capita foreign direct investment (lnfdi) and the correlation coefficient was -0.0979. Normally, foreign direct investment is supposed to bring technological spillover effects to local companies through demonstration effects, competition and transnational personnel. Technological advances can be brought about through channels such as staff training and mobility, and finally the number of patent grants can increase. However, with the rapid economic growth of the study region, the gap between the technological innovation capabilities of local and FDI companies has been gradually narrowed. The mode of innovation in the study region has changed from imitation and learning to independent innovation. With the continuous increase in foreign direct investment in the study region, the competition between local and FDI enterprises has been further aggravated. Local enterprises have to maintain profits by reducing R\&D investment, which has inhibited innovation in the study region. Therefore, the amount of patents granted shows a negative correlation with per capita foreign direct investment.

\subsection{Analysis of Regression Results}

A panel data model was established to empirically analyze the impact of innovation investment, number of innovators, economic development level, industrial structure and foreign direct investment on the innovation output of the study region. The panel data model can solve the problem of missing variables caused by individual heterogeneity and can fully reveal the effect of each independent variable on the dependent variable. In order to test the model form, the individual effect test was first performed on the panel data model. The F-statistic of the fixed-effects model was 62.99, which significantly rejects the null hypothesis that there is no individual effect. The open-statistic model had a statistic of 468.91, which also significantly rejects the null hypothesis that there is no individual effect. Second, the Hausman test was performed, and the statistic of the opening was 33.33, which significantly rejects the random effects model. Therefore, the fixed effects model was selected for use.

Table 5. Panel data model regression results.

\begin{tabular}{cccc}
\hline & OLS & FE & RE \\
$\ln Y$ & $\ln Y$ & $0.398^{* * *}$ \\
\hline \multirow{2}{*}{$\ln K$} & $0.529^{* * *}$ & $0.406^{* * *}$ & $(0.0867)$ \\
& $(0.138)$ & $(0.0792)$ & $0.268^{* * *}$ \\
$\ln L$ & $0.301^{* *}$ & $0.159^{*}$ & $(0.0882)$ \\
& $(0.146)$ & $(0.0824)$ & $0.697^{* * *}$ \\
$\ln p g d p$ & $0.648^{* * *}$ & $0.808^{* * *}$ & $(0.0986)$ \\
ser & $(0.134)$ & $(0.0924)$ & $0.0103^{* *}$
\end{tabular}




\begin{tabular}{cccc} 
& $(0.00494)$ & $(0.00530)$ & $(0.00510)$ \\
lnpfdi & $-0.594^{* * *}$ & -0.0681 & $-0.209^{* * *}$ \\
& $(0.0800)$ & $(0.0600)$ & $(0.0606)$ \\
\multirow{2}{*}{ cons } & $-8.482^{* * *}$ & $-11.71^{* * *}$ & $-9.605^{* * *}$ \\
& $(1.212)$ & $(0.964)$ & $(0.984)$ \\
$\mathrm{N}$ & 170 & 170 & 170 \\
\hline
\end{tabular}

Note: ${ }^{* * *},{ }^{* *}$ and ${ }^{*}$ indicate that the significance test of $1 \%, 5 \%$ and $10 \%$ is passed, and the standard deviation is in brackets.

According to the regression results (Table 5), the coefficient of R\&D expenditure (lnK) was found to be 0.406 and passed the $1 \%$ significance level test. This indicates that R\&D expenditure has a significant positive impact on innovation output in the study region. When other conditions remain unchanged, the innovation output level increases by $0.406 \%$ with every $1 \%$ increase in R\&D expenditure. Shenzhen's higher level of innovation output is closely related to its high R\&D expenditure, which increased from 373 million US dollars in 2000 to 114.42 billion US dollars in 2016, with an increase of 30.74 times. The number of patents granted in Shenzhen increased from 2,401 in 2000 to 75,043 in 2016, with an increase of 31.3 times. As one of the key factors affecting basic innovation and integrated innovation, $R \& D$ expenditure has a decisive influence on the level of innovation output.

The coefficient of R\&D personnel $(\operatorname{lnL})$ was 0.159 and passed the $10 \%$ significance level test. When other conditions remain unchanged, the level of innovation output increases by $0.159 \%$ with every $1 \%$ increase in the number of $R \& D$ personnel. R\&D personnel has an important influence on the level of innovation output. Increasing the number of R\&D personnel can increase the quantity and quality of innovation output. This empirical result is consistent with Liu's study (2012) on the factors affecting regional innovation capability in Guangdong Province [53].

The coefficient of per capita GDP (lnpgdp) was 0.808 and passed the $1 \%$ significance level test. This indicates that economic development level has a significant positive impact on innovation output. When other conditions remain unchanged, the level of innovation output increases by $0.808 \%$ with every $1 \%$ increase in per capita GDP. A higher level of economic development means more material support and financial guarantee for innovation activities, and thus promote innovation output. The regions with higher economic development levels tend to have higher resource allocation capabilities and the efficiency of innovation output is thus improved. This is consistent with Du's research (2018) on the innovation capabilities of China's three major urban agglomerations [52].

The coefficient of tertiary industry ratio was 0.0245 and passed the $1 \%$ significance level test. This indicates that industrial structure has a significant positive impact on innovation output. When other conditions remain unchanged, the level of innovation output increases by $0.0245 \%$ with every $1 \%$ increase in tertiary industry ratio. Because the dominant tendencies of innovation patents in different industries are different, with the upgrading of regional industrial structure and the deepening of industrial division of labor, the tertiary industry often becomes the main driving force for regional innovation and development, indicating that the empirical analysis results are consistent with expectations.

The impact of per capita foreign direct investment on the number of patents granted is not significant, indicating that increasing foreign direct investment cannot significantly improve innovation output in the study region. The reasons are as follows. First, the FDI enterprises in Guangdong Province are mainly labor-intensive enterprises, while high-tech FDI enterprises are few. Only simple processing and assembly work is completed in the study region. Therefore, it is difficult to obtain advanced high tech. Second, the entrance of FDI enterprises into the market of the study region will intensify the competition between domestic enterprises and foreign enterprises. In order to maintain the original market share, local enterprises in the study region will reduce investment in research and development to maintain profits and innovation is curbed. Third, with the rapid development of China's economy, the gap between China and foreign countries in high and new technologies is becoming smaller and smaller. The innovation mode has gradually 
transformed from imitation and learning to independent innovation, and the space for improving innovation level through foreign direct investment is gradually reduced. Therefore, foreign direct investment has no significant effect on the innovation output of the study region and Guangdong-Hong Kong-Macao greater bay area should still further strengthen its independent innovation capability.

\section{Research Conclusions and Policy Recommendations}

This paper analyzed the basic environment for innovation, the spatial pattern of innovation output and its influencing factors in the Guangdong-Hong Kong-Macao greater bay area based on the number of patents granted in 11 cities in 2000-2016 in the study region. The following conclusions were drawn. First, the study region has advantageous location, port clusters, strong economic strength, developed financial system, rational and orderly urban division of labor and modern industrial system. These resource advantages provide a continuous driving force for innovation activities in the study region. Second, there is significant spatial variation in innovation output level in the study region. The distribution of innovation output shows a multi-center network structure with Shenzhen and Guangzhou as dual centers and engines of innovation and Dongguan and Foshan as the main regions of innovation. Third, R\&D expenditure and personnel, economic development level and industrial structure can significantly and positively affect the level of innovation output in the study region, but the role of foreign direct investment is not significant.

Based on the above research conclusions and combined with the innovation and development of the study region, the following countermeasures and suggestions have been proposed for further improving its overall innovation capability:

First, investment in science and technology innovation should be increased in order to comprehensively enhance innovation capability and output. Specifically, government should increase fiscal expenditure on science and technology research and development, provide adequate financial guarantee for universities, scientific research institutions and enterprises, as well as encourage the technological innovation of venture capital institutions and their investment in entrepreneurship and innovation. In addition, talent training and attraction of talents to the study region should be strengthened. It is necessary to strengthen the training of talents in higher education institutions, establish and improve joint training in universities and enterprises, pay attention to the training strategy of high-tech, highly-skilled and applied talents, and encourage innovative talents to participate in training and communication. By continuously optimizing the high-level talent projects, the Guangdong-Hong Kong-Macao greater bay area will attract high-level innovative talents from home and abroad.

Second, regional innovation environment should be optimized and the independent innovation capability of the study region should be strengthened. Intellectual property protection mechanism should be improved to stimulate the enthusiasm and creativity of innovative personnel. In addition, government should encourage enterprises to increase investment in R\&D through fiscal and tax incentives, enhance their independent innovation capabilities, and enhance their core competitiveness. Finally, an innovation service system should be established, a reasonable assessment of the possible technology spillover effect of primary region to surrounding regions should be performed, the barriers of administrative division should be broken and the flow of innovation elements should be promoted to realize collaborative innovation between cities and surrounding regions. Therefore, the innovation quantity and quality of the study region can be enhanced.

Third, an efficient cooperation mechanism for production, education and research should be established and highly educated and highly skilled personnel should be encouraged to carry out R\&D work. The government should strengthen the cooperation and links between the various subjects of technological innovation and integrate various technological innovation resources. An innovation management organization and innovation governance system should be established across the Guangdong-Hong Kong-Macao greater bay area. In terms of knowledge innovation, the role of key laboratories and research centers at universities and research institutions should receive 
full attention. In terms of technological innovation, the cooperation and exchange between engineering technology centers and enterprise technology centers at all levels should be brought into play. The link between high-tech industrialization base and business incubator should be enhanced. In addition, the study region should not only attract investment, but also make good use of latest research results and high technology, promote technical exchange, and improve the performance of enterprise technological innovation.

Author Contributions: D.L. developed the original idea of this study, revised the manuscript and supervised the research project. C.F. performed the data analysis and original draft preparation under the supervision of the corresponding authors, directed research comments and provided quality assurance. Both authors read and approved the final manuscript.

Acknowledgments: This work was supported by National social science fund general project "study on population agglomeration and its economic growth effect in Guangdong-Hong Kong-Macao greater bay area"(18BRK024).

Conflicts of Interest: The authors declare no conflict of interest.

\section{References}

1. Avinoam, M. Innovation diffusion and regional economic development: The spatial diffusion of automobiles in Ohio. Regional Studies 1981, 15,111-122.

2. Hall, P.H.; Heffernan, S.A. More on the Employment Effects of Innovation: Technological Disemployment and Economic Growth. Journal of Development Economics 1985, 17,151-162.

3. Zeng, J.L. Innovative vs. Imitative R\&D and Economic Growth. Journal of Development Economics 2001, 64,499-528.

4. Antonelli; Cristiano. The Economic Complexity of Technology and Innovation. Regional Studies 2010, 44, 801-806.

5. Agostino, G.; Scarlato, M. Innovation, Socio-institutional Conditions and Economic Growth in the Italian Regions. Regional Studies 2015, 49, 1514-1534.

6. Romer, P.M. Endogenous technological change. Philos Economic1990, 98, 71-102.

7. Schumpeter, J.A. The theory of economic development. Journal of Political Economy 1934, 1, 170-172.

8. Schumpeter, J.A. Capitalism, socialism and democracy. Social Science Electronic Publishing1942, 27, 594-602.

9. Jaffe, Adam B. Technological Opportunity and Spillovers of R\&D: Evidence from Firms' Patents, Profits, and Market Value. American Economic Review1986, 76, 984-1001.

10. Jaffe, Adam B. Real Effects of Academic Research. American Economic Review1989, 79, 957-970.

11. Criliches, Zvi. Patent Statistics as Economic Indicators: A Survey. Journal of Economic Literature 1990, 28, 1661-1707.

12. Rodr' iguez-Pose; Andr'es; Crescenzi, R. Research and Development, Spillovers, Innovation Systems, and the Genesis of Regional Growth in Europe. Regional Studies2008, 42, 51-67.

13. Sterlacchini; Alessandro. R\&D, Higher Education and Regional Growth: Uneven Linkages among European Regions. Research Policy2008, 37, 1096-1107.

14. Marrocu; Emanuela; Raffaele Paci; Stefano Usai. Productivity Growth in the Old and New Europe: The Role of Agglomeration Externalities. Journal of Regional Science 2013, 53, 418-442.

15. Jaffe, Adam, B.; Manuel, T.; Henderson R. Geographic Localization of Knowledge Spillovers as Evidenced by Patent Citations. Quarterly Journal of Economics1993, 108, 577-598.

16. Acs, Zoltan J.; David, B. Audretsch; Maryann P. Feldman. R\&D Spillovers and Recipient Firm Size. Review of Economics and Statistics1994, 76, 336-340.

17. Audretsch; David B; Maryann P. Feldman. R\&D Spillovers and the Geography of Innovation and Production. American Economic Review1996, 86, 630-640.

18. Anselin, L.; Attila, V.; Zoltan J. Acs. Local Geographic Spillovers between University Research and High Technology Innovations. Journal of Urban Economics1997, 42, 422-448.

19. Breschi, S.; Lissoni, F. Mobility of Inventors and Networks of Collaboration: An Anatomy of Localised Knowledge Flows. Journal of Economic Geography2009, 9, 439-468.

20. Capello, R.; Caragliu, A. 2012. "Proximities and the Intensity of Scientific Relations," Paper Presented at the International Tinbergen Institute Workshop 2012, Amsterdam. 
21. Capello, R.; Lenzi, C. The Knowledge-Innovation Nexus in European Regions in Capello Roberta and Lenzi Camilla (eds.), Territorial Patterns of Innovation. An Inquiry on the Knowledge Economy in European Regions. Oxford: Routledge2013, pp. 93-126.

22. Pavitt, K. R.D. Patenting and innovative activities: A statistical exploration. Research Policy1982,11, 33-51.

23. Acs, Z.J.; Anselin, L.; Varga,A. Patents and Innovation Counts as Measures of Regional Production of New Knowledge. Research Policy2002, 31,1069-1085.

24. Jalles, J.T. How to measure innovation? New evidence of the technology-growth linkage. ResearchinEconomics2010, 64, 81-96.

25. Gerald, A.C.; Satyajit C.; Robert M.H. Urban density and the rate of invention. Journal of Urban Economics2007,61,389-419.

26. Liu, C.L.; Niu, C.C.; Han,J. Spatial Dynamics of Intercity Technology Transfer Networks in China's Three Urban Agglomerations: A Patent Transaction Perspective. Sustainability2019,11,1647-1661.

27. Breschi, S. The Geography of Innovative: A Cross-sector Analysis. Regional Studies2000, 34, 213-229.

28. Moreno R.; Pacir R.; Usai S. Spatial Spillovers and Innovative Activity in European Regions []. Environment and Planing, 2005, 37(2): 1793-1812.

29. Keller, W.Geographic localization of international technology diffusion. American Economic Review2002,92,120-142.

30. Boschma, R.A. Proximity and innovation: a critical assessment. Regional Studies 2005, 39, 61-74.

31. Fornahl, D.;Brenner T. Geographic concentration of innovative activities in Germany. Structural Change and Economic Dynamics2009,20,163-182.

32. Capello, R.; Lenzi, C. Spatial Heterogeneity in Knowledge Innovation and Economic Growth Nexus: Conceptual Reflections and Empirical Evidence. Journal of Regional Science2014, 54,186-214.

33. Balland, P.A; Rigby, D. The Geography of Complex Knowledge. Economic Georaphy2017,93,1-23.

34. Miguelez, E.; Moreno, R. Relatedness, external linkages and regional innovation in Europe. Regional Studies2018,52,688-701.

35. Paula, P.; Raquel, O.; Claudio, C.; Mariacristina, P. Interplay between regional and industrial aspects in the R\&D productivity link: Evidence from Europe. Regional Studies2018,52,659-672.

36. Yueh, L. Patent laws and innovation in China. International Review of Law and Economics2009, 29, 304-313.

37. Varga, A.; Pontikakis, D.; Chorafakis, G. Metropolitan Edison and cosmopolitan Pasteur? Agglomeration and interregional research network effects on European R\&D productivity. Journal of Economic Geography2014, 14, 229-263.

38. Piperopoulos, P.; Wu, J.; Wang, C. Outward FDI, location choices and innovation performance of emerging market enterprises. Research Policy2018, 47, 232-240.

39. Audretsch,D.B.; Feldman,M.P. R\&D spillovers and the geography of innovation and production. American Economic Review1996,86,630-640.

40. Agustí,S.B.; Josep,M.A.C.; Mercedes,T. Innovation and geographical spillovers and empirical evidence. Regional Studies2018,52,603-607.

41. Angela,T.;Sara,F. Determining the effects of open innovation: the role of knowledge and geographical spillovers. Regional Studies2018,52,632-644.

42. Sujita,S.G.; Rodgers,T. Towards Smarter Regional Development of Hong Kong Within the Greater Bay Area.Smart metropolitan regional development2018,6,101-171.

43. Eddie,C.M.;Huixun,L.;Tingting,C.;Wei,L. Deciphering the spatial structure of China's megacity region: A new bay area-The Guangdong-Hong Kong-Macao Greater Bay Area in the making. Cities2018,10,1-13.

44. Li,H.Y.; Jin,R.Y.;Ning,X.; Martin,S.; Zhang,T.Y. Prioritizing the Sustainability Objectives of Major Public Projects in the Guangdong-HongKong-Macao Greater Bay Area.Sustainability2018,10, 4110-4133.

45. Maggioni, M.A.;Nosvelli, M.; Uberti, T.E. Space versus networks in the geography of innovation: a European analysis.Papers in Regional Science 2007,86, 471-493.

46. Kerr, W.R. Break through inventions and migrating clusters of innovation.Journal of Urban Economics2010, 67, 46-60.

47. Lim,U. The Spatial Distribution of Innovative activity in U.S. metropolitan areas: Evidence from patent data. Journal of Regional Analysis and Policy2003,,33,97-126.

48. Jefferson, M. The law of the primate city.Geographical Review1939, 29, 226-232.

49. Yang,D.L.; Yang,L. Interprovincial differences and spatial dependence of life expectancy in China. Social science front2016,4,178-179. 
50. Criliches, Z.RED and Productivity: The Econometric Evidence; University of Chicago Press: Chicago, USA, 1998; pp. 347-374.

51. Kaldor, N. Economic growth and the Verdoorn Law-a comment on Mr. Rowthorn's article. Economic Journal1975, 85, 891-896.

52. Du, D.B.; Liu, S.F.; Qin, X.H.; He, S.H.The spatial and temporal pattern and influencing factors of enterprise innovation in China's three coastal city clusters.Economic Geography2018,38, 111-118. 